\title{
Superação do Preconceito e Democratização do Afeto O Papel da Jurisdição na Construção dos Direitos de Inclusão e o Princípio da Liberdade de Orientação Sexual
}

\author{
Jeferson Dytz Marin \\ Doutor em Direito - Universidade do Vale do Rio dos \\ Sinos (RS). Mestre em Direito - Universidade de Santa \\ Cruz do Sul (RS). Professor do Programa de Mestrado \\ em Direito da Universidade de Caxias do Sul - USC (RS). \\ Advogado.jdmarin@ucs.br
}

\section{Karen Irena Dytz Marin}

Mestre em Direito - Universidade de Santa Cruz do Sul

(RS). Professora da Universidade de Caxias do Sul - USC

(RS). kidmarin@ucs.br

\section{Resumo}

A liberdade de orientação sexual tem representado uma das tônicas dos debates relativos à inclusão na pós-modernidade. 0 preconceito ainda habita na sociedade, e circula, de forma indisfarçada ou latente, também na academia e no sistema jurídico. Por outro lado, a Constituição, principal instrumento jurídico de garantia dos direitos fundamentais do homem, revela-se sensível, mas sua pragmática mostra-se insuficiente à recepção do princípio da livre orientação sexual e todos os corolários que dele advêm. 0 reconhecimento da diferença na constituição da sociedade, com a valorização da diversidade enquanto riqueza antropológica, e a aplicação da igualdade jurídica, com a concessão de direitos idênticos a todos, alcançará indistintamente 0 direito à diferença e 0 direito à igualdade, infelizmente tolhido de setores marginalizados da sociedade, vítimas do preconceito e da indiferença, que representam quiçá os maiores algozes do Estado Democrático de Direito.

Palavras-chave: Igualdade/diferença. Homossexualidade. Orientação sexual. Constituição. 


\title{
LA SUPERAZIONE DEL PREGIUDIZIO E LA DEMOCRATIZZAZIONE DEL AFFETTO Il Ruolo Della Giurisdizione Nella Costruzione dei Diritti di Inclusione e il Principio Della Liberta Dell'orientamento Sessuale
}

\begin{abstract}
Riassunto
La libertà di orientamento sessuale da qualche tempo rappresenta un punto forte nei dibattiti relativi all'inclusione nel postmodernismo. II pregiudizio persiste ancora nella società e si muove di forma non mascherata o latente anche nell'accademia e nel ambiente giuridico. Dall'altra parte la Costituzione, la quale si costituisce nel pricipale strumento giuridico che assicura i diritti fondamentali dell'uomo, si rivela sensibile, però la sua pragmatica si dimostra insufficiente per accogliere il principio del libero orientamento sessuale e tutti i corollari che da esso avvengono. Il riconoscimento della differenza nella costituzione della società con la valorizzazione della diversità come ricchezza antropologica, e l'applicazione dell'uguagliaza giuridica, con la concessione di diritti identici a tutti, raggiungerà indistintamente il diritto alla differenza ed il diritto all'uguaglianza, purtroppo tolto daí settori emarginati della società, vitime del pregiudizio e dell'indifferenza, che rappresentano forse i carnefici maggiori dello Stato Democratico di Diritto.
\end{abstract}

Parole-chiavi: Uguaglianza/differenza. Omosessualità. Orientamento sessuale. Costituzione.

\section{THE OVERCOMING OF THE SEXUAL PREJUDICE \\ AND THE DEMOCRATIZATION OF AFFECTION: \\ Jurisdiction's Role in the Construction of Inclusion Rights and the Principle of Sexual Freedom}

\begin{abstract}
The freedom of sexual orientation has represented one of the keynotes in the discussions relating to the inclusion in postmodernity. Prejudice still resides in society, and circulates undisguised or in latent form, also in academic and legal system. On the other hand, the Constitution, the main legal instrument for assurance fundamental human rights, proves to be sensitive, but it's pragmatics shows to be insufficient to receive the principle of sexual freedom and all the consequences that it represents. The recognition of the difference in the society's formation, to valuing diversity as anthropological wealth, and the application of legal equality, with the granting of identical rights to everybody, without distinction, will achieve the right to difference and the right to equality, unfortunately removed from marginalized sectors of society, victims of prejudice and indifference, which perhaps represent the greatest executioners of the democratic rule of law.
\end{abstract}

Keywords: Equality / difference. Homosexuality. Sexual orientation. Constitution.

\section{Sumário}

1 Considerações Iniciais. 2 Adeus ao Patrimonialista Conservador! Relações de afeto x relações de fato. 3 À Guisa de Conclusão: o preconceito e a mudança paradigmática do Judiciário. 4 Referências. 


\section{1 - CONSIDERAÇÕES INICIAIS}

A discussão acerca da homossexualidade deixou de ser uma omissão da sociedade. Hoje, em razão da polêmica gerada pelo tema, todas as áreas científicas adotam uma postura investigativa. Impende a necessidade de um posicionamento, contrário ou favorável. Isso, ao menos, fez com que fosse sepultada parte da visão sacralizada que imperava até então, a qual considerava a homossexualidade um desvario sequer digno de apreço.

O preconceito em relação aos homossexuais, infelizmente, acompanha toda a população, incluindo os operadores do Direito, muitas vezes influenciados pelo conservadorismo e pelos paradigmas que balizaram as clássicas noções de Direito de Família, muitas das quais arcaicas e já expulsas do ordenamento moderno. Os tribunais, salvo raras exceções destacando-se, principalmente, o Estado do Rio Grande do Sul -, têm se revelado tímidos na aplicação dos princípios constitucionais que vedam qualquer espécie de discriminação, tolhendo direitos dos homossexuais, em prol de um injustificado comodismo que advoga pelo aguardo inerte de uma solução regulamentadora do poder legiferante.

Nesse contexto, uma vez postas as bases sociológico/sistêmicas, definida a evolução antropológica e a compreensão da Psicologia e da Psicanálise acerca da identidade sexual do indivíduo, parte-se para a demonstração da necessidade de um trato jurídico adequado ao tema, que importe na superação da discriminação e na aplicação real do princípio da igualdade, viabilizando consideração idêntica a todos os sujeitos de direitos inseridos na Constituição. Dessa forma, o presente texto abordará quatro aspectos: a) a constitucionalização do direito de família e a superação do paradigma patrimonialista; b) a elaboração de um estudo de Direito Comparado, enfocando o trato jurídico de diversos países do mundo no que toca à homossexualidade; c) a análise do princípio constitucional da livre orientação sexual, corolário dos princípios da igualdade e da liberdade, demonstrando a necessidade de irrestrita aplicação; d) a indicação de 
instrumentos de interpretação adequados à Constituição Federal no que toca à identidade sexual, buscando a superação do conceito tradicional de gênero, mediante a flexibilização do binômio masculino/feminino, reconhecendo-se outras formas de expressão da sexualidade.

O Direito de Família passa por um período de aturadas transformações. As alterações trazidas pela Magna Carta de 1988, alcançando aos cônjuges um patamar de absoluta igualdade, a debelação do conceito de filho espúrio, o reconhecimento da união estável e da família monoparental, mudaram decisivamente o meio jurídico.

É sabido e consabido que o patrimônio não representa o arrimo central da união dos indivíduos; é o afeto que motiva a vida em comum, que mantém a harmonia conjugal e que dá vida a qualquer relação, entretanto a barreira que encobre o olhar de muitos juristas mantém-se intacta, seguindo na contramão da evolução social.

Ora, se o afeto é o cerne de qualquer união, por que impedir a união de casais homossexuais que nutrem um sentimento que pode ser equiparado a qualquer relação heterossexual?

A tese de que a inexistência de regulamentação é motivo suficiente à vedação da tutela jurisdicional aos homossexuais não encontra amparo social e/ou jurídico plausível. O princípio da livre orientação sexual, mediante o emprego do artigo $3^{\circ}$, IV, da CF, bem como do artigo $5^{\circ}$, “caput”, empresta argumento constitucional suficiente à concessão de direitos patrimoniais oriundos da relação homossexual, de reconhecimento de parceiros na qualidade de dependentes para fins previdenciários ou privados e de combate a qualquer espécie de discriminação.

O Direito Comparado verte ampla produção doutrinária, uma vez que boa parte dos países que registram alto nível de consciência social já regulamentou a matéria, valendo citar os exemplos da Dinamarca, primeiro país a aceitar legalmente o registro da união entre homossexuais, 
Suécia, Noruega, França e Holanda, esta última, notabilizada por tornar-se, no ano de 2000, a primeira nação do mundo a disciplinar a adoção aos casais de mesmo sexo.

Já é chegado o momento de inumar essas mazelas que permeiam os poderes constituídos e emprestar de uma vez por todas, às uniões de iguais, a irrestrita tutela jurisdicional do Estado.

\section{2 - ADEUS AO PATRIMONIALISTA CONSERVADOR! RELAÇÕES DE AFETO X RELAÇÕES DE FATO}

O Direito de Família sofreu mutações altamente significativas com o advento da Carta Política de 1988, cujo constituinte pautou-se pela análise serena da realidade social, que há muito indicava a tomada dos caminhos hoje constitucionalizados.

A doutrina que imperava anteriormente à Constituição versava que a família só poderia prover de pais que tivessem passado por justas núpcias, originando uma prole "legítima", ${ }_{1}^{1}$ que reconhecia uma única entidade familiar firmada por meio do casamento, hierarquizava as relações entre os cônjuges pondo o homem como chefe da família, e patrimonializava as uniões, foi definitivamente expulsa do mundo social e jurídico.

A mulher, relegada a segundo plano, que até então priorizava as funções domésticas, passou a participar ativamente do mercado de trabalho, da política, da vida social e enfim, começou a fazer jus à igualdade entre os cônjuges expressamente prevista na Constituição.

${ }^{1}$ Posto que, à época, os filhos oriundos de relações extramatrimoniais eram tidos por espúrios e recebiam tratamento legal diverso. 
O casamento sacralizado e visto sob a ótica do estrito cumprimento dos deveres conjugais, dirigindo esforços ao acúmulo de capital, inserido num pensamento patriarcal, deu lugar a uma nova ordem de uniões, que reconheceu a estabilidade como requisito básico para a caracterização dos vínculos, atribuindo um valor bem menos relevante às formalidades. Também foram objeto de tutela da Constituição as famílias monoparentais, compostas por mãe ou pai e filho, sendo atribuído a estas igual status de entidade familiar, por meio da lembrança expressa do parágrafo $4 \square$, do artigo 226 da $\mathrm{CF}$.

Os filhos provenientes de relações conjugais ou extraconjugais passaram a gozar dos mesmos direitos, desqualificando as designações de filho legítimo e ilegítimo.

O relevo que era atribuído ao sacrifício dos cônjuges, que prezavam demasiadamente as juras postas sobre o altar matrimonial, perdeu valor, dando lugar a uma preocupação maior com a intimidade, a privacidade e o bem-estar da família, alcançando ênfase ao caráter privado e desprestigiando a relação publicista antes tão valorizada no âmbito familiar.

O Estado deixou de ter como meta de tutela central a questão patrimonial, passando a atribuir maior relevância à intimidade e à afetividade. $\mathrm{O}$ afeto passou a ser o centro das atenções nas relações familiares, dando azo à realização pessoal, individual e conjunta do casal, pondo o amor como real fator de sobrevivência da relação, deixando os casais de persistirem na vida conjugal quando o sentimento se esvai, em prol da conveniência social e da integral manutenção do patrimônio. Prova disso é a uníssona posição dos Pretórios no sentido de que, hoje, prescinde-se da prova da culpa nas ações de separação, divórcio e rompimento de união estável.

Como bem assevera Maria Claudia Crespo Brauner (2001, p. 9), desenvolvendo um pensamento moderno de Direito de Família, compatível com as evoluções protagonizadas pela Carta Magna de 1988 
(...) os objetivos inerentes à formação de uma família não se resumem na exclusiva função de dar a vida (reprodução), criar e educar os filhos. O desenvolvimento da ciência na invenção e o aprimoramento dos métodos contraceptivos trouxeram a possibilidade de se organizar os nascimentos, respeitando-se a autonomia dos indivíduos em gerar ou deixar de gerar filhos. Os esposos, cônjuges ou companheiros se devem reciprocamente, antes de tudo, afeição, dedicação e assistência mútua.

Enfim, a Constituição estabeleceu uma nova ordem familiar, sepultando tabus e sacros conceitos, introduzindo no ordenamento o primado da igualdade entre homem e mulher, dentro e fora do casamento; a pluralização das entidades familiares acompanhada da respectiva proteção estatal e igualdade de direitos concernentes aos filhos. Como lembra Luiz Edson Fachin, ${ }^{2}$ a família matrimonializada, hierarquizada, patriarcal e de feição pessoal, deixou de existir com a promulgação da Constituição de 1988. Como corolário desses direitos, pode-se citar a despatrimonialização das relações familiares, a definitiva independência da mulher, a descodificação (ou constitucionalização) do Direito de Família e o lançamento de férteis sementes que anunciam novas e necessárias transformações.

No que toca a esse novo paradigma de família, Franco Grillini (2004, p. 393-394) aponta as características que permeiam as uniões na pós-modernidade, rompendo tabus e estabelecendo o afeto e o pluralismo como esteio, o que causou uma verdadeira revolução social:

Un tempo si pensava che la famiglia, l'idea di famiglia fosse um'idea che non si metteva in discussione. Si nasceva, si cresceva, si passava l'adolescenza, ci si fidanzava a ci si sposava, si facevano i figli, si matteva in discussione. Si nasceva, si cresceva, si passava l'adolescenza, ci si fidanzava e ci si sposava, si facevano i figli, si metteva su casa e si moriva. I matrimoni erano combinati. Quase nessuno si sceglieva il partner. Ci sono fiumi di letteratura su questo tema. Con l'avvento

${ }^{2}$ Ver: Fachin, Luiz Edson. Aspectos jurídicos da união de pessoas do mesmo sexo. Revista dos Tribunais. São Paulo, vol. 732, p. 47-54, ano 85, out/1996. 
del romanticismo, com l'idea dell'amore, dell'innamoramento, il parner diventa frutto di una scelta. Sembra benale ma questa è uma gigantesca rivoluzione della modernità. Le persone si scelgono un partner sulla base delle proprie caratteristiche, dei propri bisogni, sulla base della propria idea di vita e sulla base di um progetto di realizzazione personale e anche di felicità. La scelta del partner è, come dire, l'elemento centrale dell'idea di libertà e anche della nozione stessa di libertà. Non c'è libetà senza dirrito alla scelta. ${ }^{3}$

O reconhecimento ao direito de livre expressão da sexualidade impõe-se diante da previsão constitucional que veda qualquer discriminação de ordem sexual (artigo $3^{\circ}$ IV). Isso tem ocorrido nos Tribunais, valendo lembrar as decisões que concederam direito à herança e benefícios previdenciários a parceiro homossexual. ${ }^{4}$

${ }^{3}$ Do italiano para o português: "Um tempo se acreditava que a família, a idéia de família fosse uma idéia que não se discutia. Nascia-se, crescia-se, passava-se pela adolescência, noivava-se e casava-se, se faziam os filhos, se desesperava em discussão. Nascia-se, crescia-se, passava-se pela adolescência, noivava-se e casava-se, se faziam os filhos, se desesperava em sua casa e se morria. Os casamentos eram combinados. Quase ninguém escolhia o parceiro. Há muita literatura sobre esse tempo. Com o advento do romantismo, com a idéia do amor, do namoro, o parceiro torna-se fruto de uma escolha. Parece banal, mas esta é uma gigantesca revolução da modernidade. As pessoas escolhem um par com base nas próprias características, nas próprias necessidades, com base em sua própria idéia de vida e de um projeto de realização pessoal e de felicidade. A escolha do par é, por assim dizer, o elemento central da idéia de liberdade e também da própria noção de liberdade. Não há liberdade sem direito à escolha”.

${ }^{4}$ Rio Grande do Sul. Justiça Federal. Reconhecimento do direito à admissão no Plano de Assistência Médica Supletiva - PAMS e na Funcef, de dependente que constituiu sociedade de fato com parceiro do mesmo sexo. Ricardo Pecin Couto e Izidoro de Souza Reves versus Caixa Econômica Federal. Prolator: Roger Raupp Rios. Sentença de 9 de junho de 1996. Autos da ação ordinária no 96.0002030-2.

Brasília. Superior Tribunal de Justiça. Homossexuais. Partilha dos bens comuns. Relator: Ruy Rosado de Aguiar. Recurso Especial nº 148897/MG. 4. Turma. Julgamento: 10/2/1998. 
Em relação ao reconhecimento do vínculo afetivo nas relações homossexuais, o meio jurídico tem se mostrado mais relutante, de sorte que mostra sua faceta conservadora insistindo em olhar para as relações homossexuais sob o prisma obrigacional do Direito, classificando-as como meras sociedades de fato. ${ }^{5}$

Em absoluto, não se concorda com essa posição, uma vez que se entende que a análise das uniões hetero ou homossexuais, formais ou não formais, das quais se pretende lançar mão, tem no vínculo afetivo o fator determinante da união de qualquer casal, em contraposição à teoria que propõe o reconhecimento puro e simples de uma sociedade de fato, relegando o verdadeiro animus dos parceiros que constituem a união.

Renuncia-se sim a uma certa estabilidade, na medida em que a dissolução das uniões não apresenta mais todas aquelas resistências que se punham no tempo transato, dessarte, $o$ amor e $o$ afeto passam a serem vistos como o objetivo maior do casal, em prol da busca do direito à felicidade de ambos, indistintamente; quando o amor morre, não existe mais razão de manutenção da união.

Se o afeto, porém, realmente habita agora o cerne da relação familiar e a união de duas pessoas ou de uma delas e um filho é reconhecida como entidade familiar, à luz do princípio constitucional da isonomia e do que veda qualquer tipo de discriminação em razão da raça, origem e sexo do indivíduo, por que não dar status de entidade familiar às uniões

\footnotetext{
${ }^{5}$ Rio de Janeiro. Tribunal de Justiça do Rio de Janeiro. Dissolução de Sociedade de Fato entre mulheres homossexuais. Efetiva participação na formação do patrimônio. O enriquecimento ilícito emana da sistemática do Código Civil e do pagamento indevido. Apelação Cível nº 1437/95. Relator: Des. Fernando Whitaker.

Minas Gerais. Tribunal de Alçada de Minas Gerais. Não cabe dano moral a ser reivindicado do pai e herdeiro universal do falecido, vítima de Aids, por pessoa que, tendo com este coabitado, houver assumido assistência ao doente, expondo-se publicamente, em face da omissão daquele, a quem não pode ser atribuída a culpa pela enfermidade de que o filho foi acometido. Apelação Cível no 226.040-8. 2. Câmara Cível do Tribunal de Alçada de Minas Gerais. Relator: Carreira Machado. Data do julgamento: 3/12/1996.
} 
entre pessoas do mesmo sexo? A resposta negativa a tal questionamento apresentar-se-ia extremamente incoerente diante das disposições constitucionais e mesmo ante o princípio da dignidade da pessoa humana contemplado pela Declaração Universal dos Direitos Humanos.

$\mathrm{Na}$ sociedade conservadora que predominava até bem pouco tempo - e que mesmo hoje ainda encontra adeptos - a união do casal era mantida em virtude dos interesses patrimoniais, da conveniência, da prole, e em razão do medo de enfrentar a ira da sociedade, que não via com bons olhos uma separação.

Hoje o afeto, interna e externamente, é tido como o valor maior dos vínculos que unem os casais, portanto o Direito deve necessariamente acompanhar essa evolução, a começar pela Magna Carta, desempregnando-se do caráter patrimonialista que o acompanha, bem como inumando de uma vez por todas a indevida intervenção do Estado nos relacionamentos. "O Direito não regula sentimentos, mas as uniões que associam afeto a interesses comuns, por terem relevância jurídica, fazem jus à proteção legal, independentemente da orientação sexual do par (Dias, 2000, p. 57)”.

Nessa esteira, a orientação sexual não deve servir de óbice à recognição da união de iguais como entidade familiar, pois se o afeto é o âmago de qualquer relacionamento e a Constituição traz o princípio da isonomia como um de seus baluartes, não é dado ao Estado o direito de determinar que as uniões legalmente reconhecidas tenham, obrigatoriamente, de ser constituídas por sexos opostos, empurrando os casais homossexuais à marginalidade e atribuindo-lhes, tão somente, status de sociedade de fato. A esse teor, as arguições de Maria Berenice Dias (2000, p. 54, 88): 
Ao serem inseridos no conceito de entidade familiar não só a família matrimonializada, mas também a união estável e o vínculo monoparental, foi quebrada em definitivo a posição excessivamente privilegiada do casamento como base de formação e proteção da família.

(...) Comprovada a existência de um relacionamento em que haja vida em comum, coabitação e laços afetivos, está-se à frente de uma entidade familiar, forma de convívio que goza de proteção constitucional. Nada justifica que se desqualifique o reconhecimento de sua existência. Só o fato de os conviventes serem do mesmo sexo não permite que lhes sejam negados os direitos assegurados aos heterossexuais.

José Afonso da Silva (1996, p. 218) cuida de forma específica da identidade sexual do indivíduo quando avalia a proibição de discriminação por motivo de orientação sexual. No seu entender, a abrangência de vedação de distinções de qualquer natureza, bem como de qualquer forma de discriminação, põe ao seu agasalho, também, o fator orientação sexual, pois que ele tem gerado um sem-número de manifestações preconceituosas.

Infelizmente, essa discriminação também está presente no Judiciário, que deveria ser o principal ator no combate à segregação perpetrada aos homossexuais. Roger Raupp Rios dá a receita para a superação do pensamento retrógrado daqueles que ainda insistem em negar aos homossexuais o amparo da lei. $\mathrm{O}$ avanço certamente dar-se-á por meio da “... superação de uma mentalidade heterossexista, que discrimina sem fundamentação jurídica. É preciso superar os limites de uma tradição de exclusão, onde prevalece a lógica da segregação social e jurídica das minorias, que não vêem respeitados seus direitos de reconhecimento" (Rios, 2001, p. 22).

A liberdade de orientação sexual integra a seara dos Direitos Fundamentais do Homem, portanto não é dado a nenhum dos países signatários da Declaração dos Direitos Fundamentais do Homem o direito de desrespeitá-la. Mais do que isso, é necessário que o Estado deixe a 
figura de mero espectador, aguardando, por meio do Judiciário, a apreciação das condutas discriminatórias adotadas pelos cidadãos; ele deve pautar-se por uma conduta positiva que tenha por fito a superação real das desigualdades e a asseguração legal de direitos aos homossexuais. A omissão e o descaso, sobremaneira o estatal, também configuram posturas discriminatórias. "A garantia da cidadania passa pela garantia da expressão da sexualidade, e a liberdade de orientação sexual insere-se como uma afirmação dos direitos humanos” (Dias, 2000, p. 16).

Essa sexualidade, por sua vez, não pode e não deve ser examinada restritivamente, mas sim em sentido lato, compreendendo muito mais que a cópula realizada pelo casal, alcançando os mais íntimos elos protagonizados na vivência a dois, só assim o equivocado cunho sacro e patrimonialista atribuído às relações conjugais será definitivamente expulso.

Devemos entender a sexualidade em seu sentido mais amplo e profundo para não reduzi-la apenas à genitalidade, que seria um empobrecimento de compreensão das relações humanas. Sexualidade, como tão bem já nos revelou Freud, é uma dimensão presente na totalidade da existência humana (Pereira, 2000, p. 54).

O rompimento de paradigmas tem, naturalmente, enfrentado um arrebatado embate social antes de passar pelo crivo final do legislador. Dessa forma, a sociedade traz o fato e exora incessantemente por sua positivação; os pretórios, às vezes, mesmo por meio de decisões disformes, variando de Estado para Estado, conforme os lineamentos jurídicos adotados por cada um, antecipam-se à lei e firmam jurisprudência, que, não raro, serve como forte ponto de referência ao poder legiferante; por derradeiro, como não poderia deixar de ser, arrimado nos precedentes fáticos e nas discussões protagonizadas pelos tribunais, o Estado edita a norma com o precípuo fim de levar "paz" à sociedade, aliás, atendendo o magno fito da lei, esmiuçado por Rousseau (1996). 
Quando o vozear social alcança contornos de generalidade, o caminho trilhado para o surgimento de uma norma é bem menos espinhoso, posto que as resistências a sua promulgação não encontram acento consistente; contudo, quando esse brado provém das chamadas minorias, o êxito torna-se muito mais árduo, especialmente quando essa minoria encontra arraigados na sociedade preconceitos de toda a ordem, regulados por entidades formadoras de opinião e dotadas de posições extremamente discriminatórias. Ora, o quadro não pode ser mais adverso. E o pior, é essa a situação dos homossexuais! Além de ter de enfrentar a ira da sociedade que atribui à homossexualidade conotação de depravação, descontrole e avessa conduta social, batem de frente com a Igreja Católica, cuja absoluta maioria de seus integrantes posiciona-se terminantemente contra a união de iguais, tendo-a como uma afronta à religiosidade.

Não foi diferente quando da discussão da Lei do Divórcio, da união estável, do reconhecimento da igualdade entre os filhos tidos no matrimônio e os provenientes de relações extraconjugais, da família monoparental, e enfim... O passamento de conceitos vetustos - que não mais condizem com a realidade social - tem percorrido um truculento caminho e enfrentado acaloradas discussões. Não poderia ser diferente com a busca da tutela jurídica da união de iguais.

A organização e a popularização dos movimentos de defesa de direitos dos homossexuais e dos transexuais afastaram muito do receio que essas classes de cidadãos tinham em manifestar livremente sua conduta sexual. Paralelamente, a regulamentação dos direitos atinentes às uniões de iguais em diversos países do mundo e o gradativo afastamento do preconceito que integra o Judiciário introduziu o tema no meio jurídico e social, passando, inclusive, a ser objeto de não raras abordagens dos meios de comunicação. 
Hoje, na sociedade funcionalmente diferenciada, de abertura transdisciplinar, o assunto atingiu um estágio jamais alcançado anteriormente, ensejando de parte dos técnicos das diversas áreas que guardam envolvimento direto com a questão uma postura investigativa, ou seja, a informação tem sido objeto de busca constante, a fim de dar azo à firmação de um posicionamento. Acima de tudo, porém, tornou-se pacífico o entendimento de que é necessário, de uma vez por todas, trazer o tema à luz do conhecimento técnico e científico.

A constituição desse quadro demanda definições dos órgãos estatais, mormente no que concerne à conduta do Judiciário e do Legislativo, que diante da evolução constante deste fato sociocultural, terão, necessariamente, a curto e médio prazos, que indicar caminhos para a busca de alternativas que vertam a derradeira e já tardia solução para a questão. Por certo que a fuga ao debate só levará à infrutífera senda do descaso.

O precípuo escopo da ciência jurídica é oferecer guarida às situações de fato trazidas pela constante e irrefreável evolução social. Pode-se afirmar que esta é a própria razão da existência do Direito, quando não sua primitiva fonte geradora. A união de casais do mesmo sexo é um fato concreto e cada vez mais evidente. Logo, se toda a situação de fato devidamente constatada e que alcance cunho genérico deve estar envolvida pelos braços do Direito, as uniões de homossexuais devem ser tuteladas pelo ordenamento positivo.

Ao Judiciário, cujos brocardos precedem a criação de leis estribadas nos clamores da sociedade, cabe a coragem necessária para abordar o tema como desbravador que é das primordiais questões do Direito. A sociedade também deve ser intrépide no sentido de abrir os olhos para enxergar a situação e alcançar o senso de justiça que é comum a todos. Por derradeiro, ao Legislativo, ao qual cabe a tarefa primeira de gerar as leis, resta a sensibilidade para perceber a evolução social que reveste a questão a fim de normatizá-la indiscriminadamente. $\mathrm{O}$ "direito é uma luta perma- 
nente”, como já afirmava Ihering (1996), expoente decisivo na formulação do Código Civil Brasileiro, que, a despeito da análise atual de alguns de seus institutos, hoje tidos como ultrapassados, à época da promulgação gozava do conceito de um regulamento de consistência muito significativa.

Todas as conquistas sociais estão inseridas num processo de lutas, nas quais boa parcela do Judiciário tem tomado assento, a exemplo dos direitos trabalhistas, do movimento feminista, da fixação do fim social da propriedade, etc. Não poderia ser de outra forma na questão do reconhecimento da união de iguais: os movimentos sociais dão origem à discussão, o Judiciário passa a adequar o fato ao Direito mediante decisões pioneiras e por fim, a regulamentação torna-se inevitável; esse o legítimo processo de lutas aludido por Ihering (1996).

Com efeito, aqui, muito mais do que a intensa discussão social que o tema requer, está centrado o cerne da questão. Uma lei incompatível com sua real demanda social inverte o efeito natural, desagregando o indivíduo. Assim, faz-se urgente a criação de uma norma desapegada dos antigos e sacralizados conceitos que imperavam até a promulgação da Carta Política de 1988, que inseriu no ordenamento os modernos baluartes do Direito de Família.

Uma regulamentação que tenha por arrimo o bom senso, fator determinante da união de qualquer casal - seja ele hetero ou homossexual -, disciplinará a questão com justeza e maestria. Uma norma que olhe para as uniões de casais do mesmo sexo como meras sociedades de fato, todavia, submetendo-as aos princípios do direito obrigacional, certamente representará a perda de uma oportunidade ímpar de disciplinar a matéria com a modernidade e o acerto que as discussões que atualmente cercam o Direito de Família denotam.

Não se quer um poder opressor da sexualidade, apegado à sacralização dos conceitos ditados pela religião, por vezes presos a valores que remontam à Idade Média. É sensato que o Estado adote uma postura de 
valorização e pleno reconhecimento do direito à livre orientação sexual, deixando de lado a omissão e passando a positivar a previsão de fatos que há muito integram nosso meio social.

Michel Foucault, na História da sexualidade: a vontade de saber, demonstra com peculiar maestria essa opressão estatal à sexualidade anteriormente abordada:

O ciclo da interdição: não te aproximes, não toques, não consumas, não tenhas prazer, não fales, não apareças; em última instância, não existirás, a não ser na sombra e no segredo. Sobre o sexo, o poder só faria funcionar uma lei de proibição. Seu objetivo: que o sexo renunciasse a si mesmo. Seu instrumento: a ameaça de um castigo que nada mais é do que sua supressão. Renuncia a ti mesmo sob pena de seres suprimido; não apareças se não quiseres desaparecer. Tua existência só será mantida à custa de tua anulação. O poder oprime o sexo exclusivamente através de uma interdição que joga com a alternativa entre duas existências (Foucault, 2002, p. 81).

No campo jurídico o tema requer algumas indagações, que levam à verificação da existência de argumentos relevantes no sistema vigente, mas também à necessidade de revisão de previsões que não se coadunam com a evolução social. Nesse sentido, embora o paradigma constitucional trazido pelo artigo $3^{\circ}$, IV e artigo $5^{\circ}$, “caput”, tenha vedado qualquer forma de discriminação, assegurando o livre-exercício da sexualidade, a previsão do artigo 226, parágrafo $3^{\circ}$, que impõe a diversidade de sexos para o reconhecimento da união estável, traz a exata representação do preconceito latente e guarda, em seu âmago, caráter discriminatório, assim como o Projeto de Lei $\mathrm{n}^{0}$ 1.151/95, de autoria da então deputada Marta Suplicy.

Mediante a aplicação da igualdade formal, busca-se o reconhecimento dos homossexuais enquanto pessoas integrantes da sociedade, como um autêntico processo de inclusão social. Diferenciar os homo dos heterossexuais sob o ponto de vista dos direitos que a eles pertine significa aceitar a discriminação pela diferença. 
Embora o reconhecimento da diferença seja uma das formas mais ricas de inclusão, fomento à diversidade cultural e aceitação das diferentes personalidades que compõe a sociedade, a reprodução dessa diferença sob o ponto de vista legal, mediante a concessão distinta de direitos constitucionais, representa clara afronta ao princípio da igualdade formal.

O artigo 226, $\S 3^{\circ}$, nessa linha, representaria uma norma constitucional inconstitucional? O paradoxo das normas "constitucionais inconstitucionais” alcança especial análise na obra de Otto Bachof, professor da Universidade de Tübingen. O presente caso encontra conformação com a possibilidade de reconhecimento da inconstitucionalidade de normas constitucionais que registram contradição com outras, de grau superior, bem como na hipótese de cessação de vigência sem disposição expressa.

Na primeira hipótese reconhecer-se-ia a inconstitucionalidade implícita do artigo $226, \S 3^{\circ}$, diante da previsão do artigo $5^{\circ}$ “caput” $e$ artigo $3^{\circ}$, IV, todos da CF. O primeiro, formalmente constitucional, encontra divergência material com os últimos, porquanto protagoniza discriminação de ordem sexual em razão da imposição da diversidade de sexos na constituição da união estável.

Nesse sentido, o posicionamento de Bachof (1994, p. 58-59):

(...) no caso de uma contradição aparente entre um princípio constitucional e uma norma singular da Constituição, tal vontade só pode em princípio ser entendida, ou no sentido de que o legislador constituinte quis admitir essa norma singular como excepção à regra, ou no de que negou, pura e simplesmente, a existência de semelhante contradição. Conceder-se-á, todavia, que em casos de contradição insolúvel, de uma contradição que também não seja susceptível de interpretar-se através da relação regra-excepção, assim como, por último, em caso de manifesto equívoco, possa haver lugar para outro juízo. 
Assim, a constitucionalidade material dos artigos $5^{\circ}$ e $3^{\circ}$, IV, superaria a constitucionalidade meramente formal do artigo $226, \S 3^{\circ}$, norma constitucional de hierarquia inferior.

Diante dessa situação de incompletude e incoerências relativas, a hermenêutica fundamentada na concepção de que o ordenamento jurídico é um conjunto de normas e essas são divididas entre princípios e regras, com aplicação da proporcionalidade e da razoabilidade na compreensão dos direitos fundamentais, surge como caminho possível. ${ }^{6}$

Afora a teoria de Bachof, Robert Alexy, em sua clássica concepção das antinomias jurídicas próprias e impróprias, mediante o emprego de uma hermenêutica adequada oferece a solução para o aparente paradoxo. Havendo a verificação de conflito entre uma regra e um princípio - uma antinomia jurídica própria - deve prevalecer sempre o segundo, tendo em

${ }^{6}$ Bohn, Claudia Fernanda Rivera. A Teoria dos Direitos Fundamentais de Robert Alexy. In: Dobrowolski, Silvio. A Constituição no Mundo Globalizado. Florianópolis: Diploma Legal, 2000, p. 139, em resumo, aduz: "As normas de direito fundamental se dividem em regras e princípios. Tanto o princípio como as regras são normas, pois ambos emitem um 'dever ser' e seus enunciados são compostos pelas expressões deônticas básicas. Em outros termos, tanto as regras quanto os princípios são razões para juízos concretos de dever ser. Apesar das semelhanças entre os princípios e regras é importante estabelecer as duas diferenças, que para Alexy são de caráter qualitativo. Uma diferença apontada pelo autor está no próprio conceito de cada uma dessas normas, onde as regras são normas que solo pueden ser cumplidas o no. Si una regra és valida, entonces de hacerse exactamente lo que ella exige, ni más ni menos. Por lo tanto, las reglas contienen determinaciones en el ámbito de lo fáctica y jurídicamente posible'. Os princípios, por outro lado, compõem aquelas normas que "ordenan que algo sea realizado en la mayor medida posible, dentro de las posibilidades jurídicas e reales existentes. Por lo tanto, los principios são mandatos de optimización, que están caracterizados por el echo de que pueden ser cumplidos em diferente grado y que la medida debida de su cumplimento no sólo depende de las posibilidades reales sino también de las jurídicas.” Do espanhol para o português: “que só podem ser cumpridos ou não. Se uma regra é válida, então deve-ser fazer exatamente o que determina, nem mais nem menos. Portanto, as regras contêm determinações no âmbito do fática e juridicamente possível. Os princípios, por outro lado, compõem aquelas normas que "ordenam que algo seja realizado na maior medida possível, dentro das possibilidades jurídicas e reais existentes. Portanto, os princípios são mandatos de otimização, que estão caracterizados pelo eixo de que podem ser cumpridos em diferentes graus e que na medida exata de seu cumprimento não só dependem das possibilidades reais, mas também das jurídicas”. 
vista seu conteúdo largo e informador do Direito, especialmente quando se cuida de garantias individuais, que, para muitos constitucionalistas, são as cláusulas pétreas por excelência (Alexy, 1997).

Para Alexy, o que diferencia princípios de regras é o fato de que os primeiros constituem razões prima facie, enquanto as segundas seriam razões definitivas. E é exatamente aí que reside a questão acerca do conflito de princípios, porque estes parecem se aplicar a todas as situações. Isso, no entanto, somente prima facie, pois pode ser que no caso concreto um princípio deixe de ser aplicado para se escolher outro, dado que eles não são normas definitivas: é a questão da tensão entre princípios.

O presente caso parece ser um clássico tipo de conflito entre um(ns) princípio(s) e uma regra, não compreendendo aquela concepção genérica de alargamento indevido dos princípios constitucionais. Nessa linha, as ponderações de Alexy (Bachof, 1994, p. 100):

Un principio es soslayado cuando en el caso que hay que decidir, un principio opuesto tiene un peso mayor. En cambio, una regla todavía no es soslayada cuando en el caso concreto el principio opuesto tiene un mayor peso que principio que apoya la regla. Además, tienen que ser esquivados los principios que establecen que reglas que son impuestas por una autoridad legitimada para ello tienen que ser seguidas y que no debe apartarse sin fundamento de una práctica transmitida. ${ }^{7}$

No presente caso, os princípios (artigo $3^{\circ}$, IV e artigo $5^{\circ}, c a p u t$ ) que se correlacionam com a regra insculpida no artigo $226, \S 3^{\circ}$, guardam carga valorativa extensa e têm o condão de afastar a regra constitucional,

${ }^{7}$ Do espanhol para o português: "Um princípio é afastado quando no caso que tem que ser decidido, um princípio oposto tem um peso maior. Doutro lado, uma regra não é afastada quando no caso concreto o princípio oposto tem um maior peso que o princípio que apoia a regra. Ademais, têm de ser relegados os princípios que estabelecem que regras que são impostas pela autoridade legitimada para isso têm de ser seguidas e que não devem distanciar-se sem fundamento de uma prática transmitida”. 
porquanto há colisão entre a previsão que tutela a liberdade de orientação sexual e a que determina a diversidade de sexos para o exercício do afeto mediante a vida em comum, retirando dos homossexuais tal direito, que é uma das consequiências do exercício pleno da identidade sexual do indivíduo.

Também com fulcro na ideia de Bachof, é possível reconhecer-se a inconstitucionalidade de uma norma constitucional em razão da "mudança de natureza”, ou seja, diante do decurso do tempo, aquela norma não encontra mais guarida na compreensão atual do Direito, encontrando-se descontextualizada e em dissonância com os princípios constitucionais que sugerem a ideia geral da norma fundamental.

Nessa linha, a imposição de diversidade de sexos, ante a igualdade formal e material como princípios informadores de todo o sistema jurídico, mesmo com a escolta da norma infraconstitucional - o Novo Código Civil, Lei $10.406 / 2002$, redundaria em inconstitucionalidade do artigo 226 , $\S$ $3^{\circ}$, norma dita por discriminatória diante do princípio da isonomia e seus desdobramentos hermenêuticos.

Bachof (1994, p. 59-60), ao examinar a teoria de Krüger, argumenta que:

(...) A transição de uma norma transitória numa norma permanente, a operar-se depois do decurso de um período transitório adequado, representará uma inconstitucionalidade: sendo assim, só ulteriormente, por conseguinte, a norma viria a tornar-se inconstitucional. (...) Não irei negar em princípio a possibilidade de uma tal mudança de natureza, nem as consequiências tiradas por Krugüer. Se certos pressupostos, que formam determinantes para o legislador emitir uma norma jurídica, não vierem a verificar-se, ou se falham as expectativas que manifestamente se ligaram à norma jurídica, pode a norma, certamente, perder o sentido. Mas, em regra, será então tarefa do legislador tirar daí as consequiências e modificá-la. No entanto, em vista da particular missão de integração da ordem constitucional, será lícito admitir também como 
possível que normas singulares da Constituição se tornem automaticamente obsoletas, quando as mesmas, em consequiência da mudança da situação real, já não puderem cumprir sua função integradora, e porventura comecem até a desempenhar uma função desintegradora.

Dessa forma, são três as teorias que guarnecem o reconhecimento da inconstitucionalidade do artigo 226, § $3^{\circ}$ da CF. A saber: a) $\mathrm{O}$ artigo 226, $\S 3^{\circ}$ é materialmente inconstitucional frente à previsão do artigo $3^{\circ}$, VI e artigo $5^{\circ}$, caput, porquanto, a partir do momento que exige diversidade de sexos para a constituição de uma união afetiva, gera diferenciação negativa; b) os artigos $3^{\circ}$, IV e $5^{\circ}$, caput, representam princípios constitucionais, ao passo que o artigo $226, \S 3^{\circ}$, traduz uma regra. Verificado a antinomia jurídica imprópria descrita por Alexy, deve prevalecer o princípio, afastando, naquele caso concreto, a regra constitucional; c) também segundo a teoria de Bachof, uma norma que muda sua natureza, encontrando-se em desacordo com as regras gerais ditadas pela Constituição e a evolução social, perde sua força normativa.

\section{3 - À GUISA DE CONCLUSÃO: O PRECONCEITO E A MUDANÇA PARADIGMÁTICA DO JUDICIÁRIO}

O fato social está posto. É evidente. As relações homossexuais existem e é cada vez maior o número de pessoas que assume publicamente sua verdadeira orientação sexual, vencendo os preconceitos, às vezes até violentos, que desejam ver a sexualidade homoafetiva reprimida.

Muitos argumentam que a homossexualidade é passível de tratamento psicológico e o retorno ao que chamam de "exercício natural da sexualidade” é alcançável. Em primeiro lugar, é de se ressaltar que a heterossexualidade não pode ser tida como um padrão de sexualidade estanque que rejeita todas as demais formas de manifestação dos desejos. Não há um estereótipo a ser seguido. Não há regra. O certo é que não é 
dado a ninguém o direito de dissimular e vexar a sexualidade de outrem. O direito de livre expressão da sexualidade é imanente ao indivíduo e não deve encontrar barreiras num sentimento social de aversão e que tende a marginalizar condutas desviadas da heterossexualidade.

Ademais, pesquisas demonstram (Relatório de Kinsey e Queer Theory) que não há grandes diferenças entre as condutas apresentadas pelos heterossexuais e pelos homossexuais, não havendo razão alguma para as atitudes discriminatórias como as que rotulam os homossexuais de marginais, pondo em xeque o pensamento daqueles que classificam homossexualidade e heterossexualidade como conceitos bifurcados. Nesse sentido, o estudo de Gonsiorek, citado na obra Homossexualidade no Direito, de autoria de Roger Raupp Rios:

Uma abordagem sociológica, por sua vez, conclui dentre outros dados, pela: (1) similitude das características psicológicas entre heterossexuais e homossexuais; (2) mesmo grau de utilização de álcool e drogas proibidas entre heterossexuais e homossexuais; (3) satisfação generalizada consigo mesmo entre os homossexuais não afeminados, tendo os afeminados manifestado maior tendência à ansiedade; (4) compatibilidade da condição homossexual com os padrões de saúde mental (a boa constituição psíquica dos homossexuais se comprova pela superação da sobrecarga de tensões a que geralmente são submetidos); (5) mesmo nível de crítica, entre os homossexuais e heterossexuais, relativo à prostituição; (6) inexistência de uma sociedade homossexual incrustada na heterossexual, devendo-se falar em relação homossexual num meio heterossexual. ${ }^{8}$

Por certo que os homossexuais restam acometidos de certas tensões, isso em razão da rejeição social e dos paradigmas contrários que têm de enfrentar. Imagine-se um adolescente que se encontra em pleno desen-

${ }^{8}$ Apud Rios, Roger Raupp. A homossexualidade no Direito. Porto Alegre: Livraria do Advogado, 2001. p. 137. 
volvimento de sua personalidade, em mutação corporal, na descoberta da sexualidade. Vive ele numa sociedade que rechaça as formas de expressão da sexualidade que não condizem com o padrão heterossexual. Então, ele volta-se à lei, ao Direito, à Justiça. Também encontra repressão, pois não vê, em momento algum, a clara asseguração dos direitos que procura. De sublinhar que embora a Constituição vede qualquer tipo de discriminação advinda da ordem sexual do indivíduo, alguns ainda insistem em interpretar o dispositivo que cuida dos direitos fundamentais do homem de forma tendenciosa, excluindo do abrigo da norma as relações entre iguais.

Qual a reação que um jovem, propendente à homossexualidade, terá diante de todo este estigma? Naturalmente que será um sentimento de repulsa e de revolta, tendendo sempre a ocultar sua sexualidade. $\mathrm{Na}$ maioria das vezes prevalece o sentimento de vergonha diante do desvio da padronização sexual imposta pela sociedade, que o coloca à margem, reprimindo o homoerotismo que a ele é inerente. Apenas uma minoria, que consegue superar esses obstáculos, é que acaba assumindo sua orientação sexual, enfrentando com invejável coragem a repressão e a aversão.

Os dilemas psicológicos que atualmente tanto afligem os homossexuais e a opção por uma vida marginal, por meio da "busca dos porões", certamente serão diminuídos de forma drástica pela regulamentação da matéria, que, por sua vez, certamente redundará na gradativa aceitação da sociedade, assim como ocorreu com o divórcio, a família monoparental e a participação social das mulheres, baluartes da luta social brasileira.

$\mathrm{Na}$ Europa são inúmeros os países que já regularam as relações homoafetivas. É necessário que o Brasil demonstre também que está sintonizado com as modernas concepções da Psicologia e da Ciência Jurídica, regulando de uma vez por todas o tema e pondo fim à angústia dos homossexuais, retirando-os das vias marginais da sociedade e permitindo que expressem livremente sua sexualidade. 
Expressões como vínculos patrimoniais, filhos espúrios, patriarcalismo, renúncia, sofrimento, conveniência, hierarquia familiar e mulher honesta devem dar lugar a outras como amor, afeto, livre expressão da sexualidade e respeito à orientação sexual do indivíduo. Esse é o novo vocabulário jurídico do Novo Direito Afetivo de matriz constitucional, que tutela o respeito às individualidades, à igualdade e à busca da felicidade como supremos valores.

\section{4 - REFERÊNCIAS}

ALEXY, R. Teoria de los derechos fundamentales. Madrid: Centro de Estudios Constitucionales, 1997.

BACHOF, O. Normas constitucionais inconstitucionais? Tradução José Maunel M. Cardoso da Costa. Coimbra: Almedina, 1994.

BOHN, C. F. R. A teoria dos direitos fundamentais de Robert Alexy. In: DOBROWLOSKI, S. A constituição no mundo globalizado. Florianópolis: Diploma Legal, 2000.

BRAUNER, M. C. P. (Org.). O direito de família: descobrindo novos caminhos. São Leopoldo: Edição da Autora, 2001.

DIAS, M. B. União homossexual - o preconceito e a justiça. Porto Alegre: Livraria do Advogado, 2000.

FACHIN, L. E. Aspectos jurídicos da união de pessoas do mesmo sexo. Revista dos Tribunais, São Paulo, vol. 732, ano 85, p. 47-54, out./1996.

. Teoria crítica do direito civil. Rio de Janeiro: Renovar, 2000.

FOUCAULT, M. A problematização do sujeito: psicologia, psiquiatria e psicanálise. Tradução Vera Lúcia Avellar Ribeiro. Org. Manoel Barros da Motta. 2. ed. Rio de Janeiro: Forense, 2002.

. História da Sexualidade. I: a vontade de saber. Tradução Maria Thereza Costa Albuquerque e J. A. Guilhon Albuquerque. 14. ed. Rio de Janeiro: Edições Graal,2001. 
FOUCAULT, M. História da sexualidade II: o uso dos prazeres. Tradução Maria Thereza Costa Albuquerque e J. A. Guilhon Albuquerque. 10. ed. Rio de Janeiro: Edições Graal, 1990.

. História da Sexualidade. III: o cuidado de si. Tradução Maria Thereza Costa Albuquerque. 1. ed. Rio de Janeiro: Edições Graal, 1985. . Microfísica do Poder. 17. ed. Tradução Roberto Machado. Rio de Janeiro: Edições Graal, 1979.

GRILLINI, F. I diritti degli omosessuali. In: FINELLI, Roberto et al. (Orgs.). Globalizzazione e diritti futuri. Roma: Università e Ricerca Scientifica, 2004.

IHERING, R. V. A luta pelo direito. Tradução João de Vasconcelos. 16. ed. Rio de Janeiro: Forense, 1996.

PEREIRA, R.C. (Coord). A família na travessia do milênio. CONGRESSO BRASILEIRO DE DIREITO DE FAMÍLIA, 2., 2000, Belo Horizonte; Del Rey. Anais... Belo Horizonte; Del Rey, 2000.

RIOS, R. R. A homossexualidade no Direito. Porto Alegre: Livraria do Advogado, 2001.

. O princípio da igualdade e a discriminação por orientação sexual. A homossexualidade no direito brasileiro e norte-americano. São Paulo: Revista dos Tribunais, 2002.

ROUSSEAU, J. J. O contrato social. Tradução Antonio de Pádua Danesi. 3. ed. São Paulo: Martins Fontes, 1996.

SILVA, J. A. Curso de Direito Constitucional Positivo. 11 ed. São Paulo: Malheiros Editores, 1996.

Recebido em: 29/7/2015

Aceito em: 2/8/2015 